\title{
Right Ventricular Diastolic Filling in the First Day of Life
}

\author{
Kenji Harada, Terukazu Shiota, Yasushi Takahashi, \\ Takashi Suzuki, Masamichi Tamura and \\ Goro TAKADA \\ Department of Pediatrics, Akita University School of \\ Medicine, Akita 010
}

\begin{abstract}
Harada, K., Shiota, T., Takahashi, Y., Suzuki, T., Tamura, M. and TAKadA, G. Right Ventricular Diastolic Filling in the First Day of Life. Tohoku J. Exp. Med., 1994, 172 (3), 227-235 — To evaluate the effects of altered preload on the Doppler flow pattern of right ventricular inflow in the first day of life, serial Doppler echocardiography of the pulmonary artery (PA) and tricuspid valve was performed in 16 normal neonates at 2,12 , and $24 \mathrm{hr}$. A computerinterfaced digitizer pad was utilized to measure the followings: PA flow velocitytime integral, total transtricuspid flow velocity-time integral, flow velocity-time integral of early diastolic filling ( $\mathrm{E}$ area), and flow velocity-time integral of atrial contraction (A area). The PA flow velocity-time integral, total transtricuspid flow velocity-time integral, $\mathrm{E}$ area, $\mathrm{A}$ area, peak $\mathrm{E}$, and peak $\mathrm{A}$ were increased significantly by $24 \mathrm{hr}$ compared with the values at $2 \mathrm{hr}$ of age. However, the peak $\mathrm{E} / \mathrm{A}, \mathrm{E} / \mathrm{A}$ area and peak $\mathrm{E} /$ total transtricuspid flow velocity-time integral did not show significant changes from 2 to $24 \mathrm{hr}$. The ductus arteriosus size was inversely correlated with the peak $\mathrm{E}(\mathrm{r}=-0.46, p<0.05), \mathrm{E}$ area $(\mathrm{r}=-0.37, p<0.05)$, and $\mathrm{A}$ area $(\mathrm{r}=-0.34, p<0.05)$. Therefore, the increase in right ventricular preload at $24 \mathrm{hr}$ is considered to be due to the cessation of the left-to-right shunt through the ductus arteriosus. These results suggest that the pattern of early and late diastolic filling of the right ventricle were dependent on the increase in preload. We can therefore conclude that the redistribution of transtricuspid flow induced by the preload condition should be taken into account to interprete the transtricuspid velocity pattern in terms of diastolic function. — right ventricular diastolic function; neonate; ductus arteriosus
\end{abstract}

Pulsed Doppler echocardiography has recently been used to assess right ventricular diastolic filling in a variety of diseases including valvular pulmonic stenosis, pulmonary hypertension, constrictive pericarditis and cardiac tamponade (Appleton et al. 1988; Hatle et al. 1989; Klein et al. 1990; Vermilion et al. 1990,

Received December 21, 1993; revision accepted for publication February 8, 1994.

Address for reprints: Kenji Harada, MD, Department of Pediatrics, Akita University School of Medicine, 1-1-1 Hondo, Akita 010, Japan.

Abbreviations: PA, pulmonary artery; $\mathrm{E}$ area, flow velocity-time integral of early diastolic filling; A area, flow velocity-time integral of atrial contraction; Peak E, peak velocity of early diastolic filling; Peak A, peak velocity of atrial contraction; E/A area, ratio of $\mathrm{E}$ area to $\mathrm{A}$ area. 
1991 ; Nascimento et al. 1991). More recently, interest has been directed toward the possibility of using Doppler echocardiography to assess right ventricular diastolic hemodynamics in newborns (Wilson et al. 1987; Johnson et al. 1988; Riggs et al. 1989). The loading condition of the right ventricle changes markedly during the transition from fetal to neonatal circulation, and continues to be unstable shortly after birth. Among the hemodynamic factors affecting left and right ventricular diastolic filling, preload appears to play an important role, as documented by recent studies (Choong et al. 1987; Courtois et al. 1988; Triulzi et al. 1990; Odake et al. 1991; Castini et al. 1992). We have demonstrated the effects of a patent ductus arteriosus on left ventricular diastolic filling (Harada et al. 1994) However, the impact of changes in preload on the transtricuspid flow pattern in this period is less clear. The purpose of our present study was to evaluate the serial changes of right ventricular filling patterns in normal neonates during their transition to postnatal circulation.

\section{Methods}

Study population. The study population consisted of 16 normal term neonates. Their mothers had uncomplicated pregnancies with no evidence of toxemia, diabetes mellitus, or pregnancy-induced hypertension. None of the infants were acutely ill or showed any evidence of congenital malformations. The mean birth weight was $3,093 \pm 381$ gm (mean \pm S.D.) and the mean gestational age was $39 \pm 1$ weeks. Each mother received explanation of the study and gave informed consent. Serial echocardiographic examinations were performed on each subject at 2,12 , and $24 \mathrm{hr}$.

Examination technique. A complete two-dimensional echocardiographic examination was performed on the subjects with the use of ultrasonoscope with a $5.0 \mathrm{MHz}$ transducer (SSD 870; Aloka, Tokyo). The size of the Doppler sample volume was set at an axial length of $2 \mathrm{~mm}$, and a wall filter setting of $400 \mathrm{~Hz}$ was used. All neonates were examined while they were lying quietly in the supine position breathing room air. To record the right ventricular inflow velocity profile, a standard four chamber view was visualized and the Doppler sample volume was placed in the inflow area of the right ventricle just below the level of the tricuspid annulus; its position was adjusted until the maximal flow velocities were recorded. Pulmonary artery (PA) flow was measured from the short axis view. The sample volume was placed in the pulmonary artery immediately distal to the pulmonary valve. Care was taken to perform these studies with the transducer beam as close to parallel to the presumed blood flow direction as possible. The angle between the estimated direction of blood flow and the Doppler beam was 20 degrees or less in the selected planes, and no angle correction of the Doppler signal was made. All examinations were recorded at a paper speed of $100 \mathrm{~mm} / \mathrm{sec}$. The subject's electrocardiogram and respiration (using a pressure transducer placed against the abdominal wall) were simultaneously recorded. The Doppler measurements were obtained during expiration. With the aid of a computerinterfaced digitizer pad (Cardio 500; Kontron Instrument, Tokyo), the various Doppler flow indices were measured from the pulmonary arterial flow and transtricuspid flow (Fig. 1). These indices included the PA flow velocity-time integral, the area under the $\mathrm{E}$ and $\mathrm{A}$ portions of the diastolic flow velocity-time integral ( $\mathrm{E}$ area and $\mathrm{A}$ area, respectively), the area under the total transtricuspid flow velocity-time integral and the peak $\mathrm{E}$ and $\mathrm{A}$ velocities (peak $\mathrm{E}$ and peak $\mathrm{A}$, respectively). The total flow velocity-time integral was defined as the total area under the velocity envelop throughout diastole. The $\mathrm{E}$ area and the $\mathrm{A}$ area were measured as the triangular portion under the Doppler curve formed by 

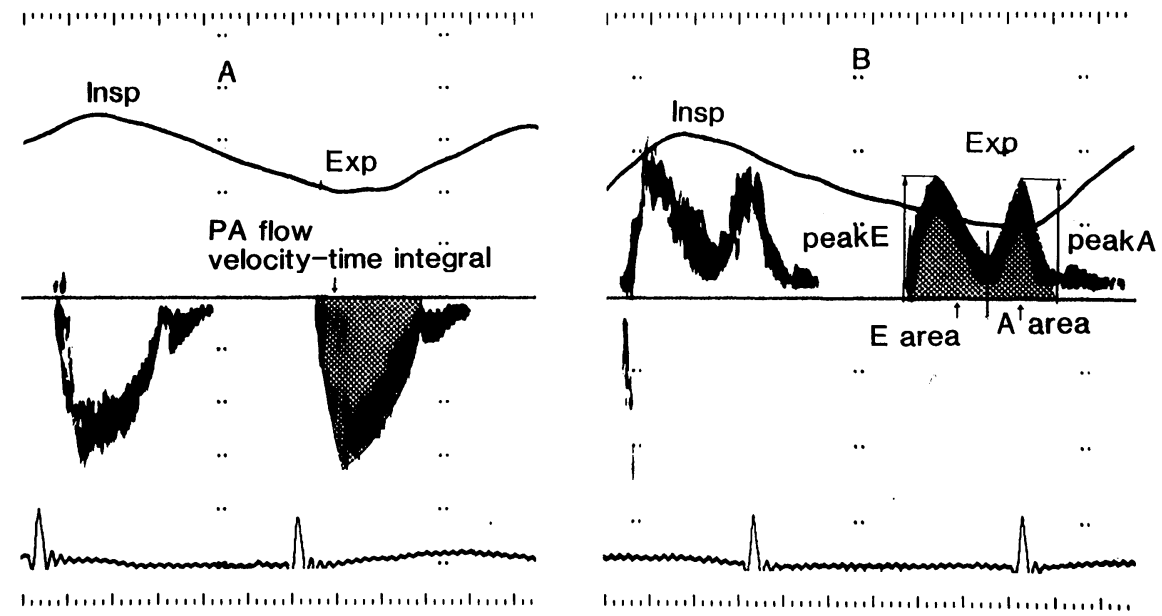

Fig. 1. Doppler flow velocity measurements. A: Ascending aortic flow velocity profile. B: Transtricuspid flow velocity profile. Insp, inspiration; Exp, expiration. peak $\mathrm{E}$, peak velocity of early diastolic filling; peak $\mathrm{A}$, peak velocity of atrial contraction; $\mathrm{E}$ area, flow velocity-time integral of early diastolic filling; A area, flow velocity-time integral of atrial contraction.

extrapolating a straight line down from the peak $\mathrm{E}$ and peak $\mathrm{A}$ velocities to the baseline. When the early and late diastolic waveforms overlapped, the $\mathrm{E}$ and $\mathrm{A}$ areas were calculated by dropping a vertical line to the baseline from the intersection of the early diastolic and late diastolic waves. The peak $\mathrm{E}$ was identified as the maximal deflection in the velocity profile before the onset of atrial contraction. The peak A was defined as the maximal deflection in the second half of diastole. From these measurements, the followings were calculated: the ratio of $\mathrm{E}$ area to $\mathrm{A}$ area (E/A area); the ratio of peak $\mathrm{E}$ to total transtricuspid flow velocity-time integral (peak $\mathrm{E} /$ total transtricuspid flow velocity-time integral); and the ratio of peak $\mathrm{E}$ to peak $\mathrm{A}$ (peak $\mathrm{E} / \mathrm{A}$ ).

Ductus arteriosus. The inner diameter of the ductus arteriosus was obtained serially after birth along with other hemodynamic measurements. The size of the ductus arteriosus was determined from the inner diameter on the two-dimensional color echocardiographic images. The inner diameter was measured at the narrowest portion of the ductal lumen in the parasternal long-axis plane. The ductus arteriosus was considered closed when the color image and shunt flow were no longer detectable.

Interobserver and intraobserver variability. To determine the interobserver and intraobserver variability of Doppler echocardiographic measurements, variables were analyzed in 10 randomly selected patients by two independent observers and by one observer on two different occasions. For determination of inter- and intraobserver variability, the means of the absolute differences between the two observers and those between the two occasions were calculated and expressed as a percentage. Data are presented as mean \pm S.D.

Statistical analysis. The data are presented as the mean \pm s.D. The Tukey-Kramer multiple comparison procedure was used to evaluate the differences in a set of measurements from 2 to $24 \mathrm{hr}$. Spearman's correlation coefficients were calculated in order to relate the ductus arteriosus size and indices of right ventricular diastolic filling. Results with $p$ values less than 0.05 were considered to be statistically significant. 


\section{Results}

Intraobserver and interobserver variability of Doppler flow measurements. Interobserver variability for PA flow velocity-time integral, total transtricuspid flow velocity-time integral, $\mathrm{E}$ area, $\mathrm{A}$ area, and $\mathrm{E} / \mathrm{A}$ area were less than $8.0 \%$ $(0.4-19.8 \%)$. Intraobserver variability for these variables was less than $7.8 \%$ $(0-18.2 \%)$.

The results of measurements of the Doppler flow indices in the normal neonates are summarized in Table 1.

Heart rate. The mean heart rates of pulmonary artery and tricuspid valve did not show any statistically significant changes from 2 to $24 \mathrm{hr}$.

Doppler flow indices. PA flow velocity-time integral, total transtricuspid flow velocity-time integral, $\mathrm{E}$ area, and peak $\mathrm{E}$ were at the lowest level at $2 \mathrm{hr}$ $(7.12 \pm 1.14 \mathrm{~cm}, 6.12 \pm 0.56 \mathrm{~cm}, 2.84 \pm 0.48 \mathrm{~cm}$, and $34.5 \pm 5.6 \mathrm{~cm}$, respectively). During the first $12 \mathrm{hr}$, the PA flow velocity-time integral, total transtricuspid flow velocity-time integral, $\mathrm{E}$ area, and peak $\mathrm{E}$ increased to $8.49 \pm 2.79 \mathrm{~cm}(p<0.05)$, $7.04 \pm 1.05 \mathrm{~cm}(p<0.05), 3.68 \pm 0.67 \mathrm{~cm} \quad(p<0.01)$, and $38.8 \pm 4.2 \mathrm{~cm}(p<0.05)$, respectively, whereas by $24 \mathrm{hr}$ the values increased further to $10.74 \pm 2.25 \mathrm{~cm}$, $7.64 \pm 1.27 \mathrm{~cm}, 3.90 \pm 0.96 \mathrm{~cm}$, and $42.2 \pm 7.3 \mathrm{~cm} / \mathrm{sec}$ (all $p<0.01$ ), respectively. The $\mathrm{A}$ area and peak $\mathrm{A}$ at $24 \mathrm{hr}$ increased significantly compared with the values at $2 \mathrm{hr}(3.75 \pm 0.47 \mathrm{~cm}$ vs. $3.17 \pm 0.48 \mathrm{~cm}[p<0.01]$ and $49.3 \pm 7.9 \mathrm{~cm} / \mathrm{sec}$ vs. $42.7 \pm$

TABLE 1. Echocardiographic measurements (mean 土s.D.)

\begin{tabular}{lllc}
\hline & \multicolumn{3}{c}{ Age } \\
\cline { 2 - 4 } & \multicolumn{1}{c}{$2 \mathrm{hr}$} & $12 \mathrm{hr}$ & $24 \mathrm{hr}$ \\
\hline PA HR (beats/min) & $129 \pm 16$ & $123 \pm 13$ & $120 \pm 13$ \\
PA flow velocity-time integral (cm) & $7.12 \pm 1.14$ & $8.49 \pm 2.79^{*}$ & $10.74 \pm 2.25^{* *}$ \\
TV HR (beats/min) & $117 \pm 7$ & $113 \pm 9$ & $113 \pm 9$ \\
Total transtricuspid flow velocity-time & $6.12 \pm 0.56$ & $7.04 \pm 1.05^{*}$ & $7.64 \pm 1.27^{* *}$ \\
$\quad$ integral (cm) & & & \\
E area (cm) & $2.84 \pm 0.48$ & $3.68 \pm 0.67^{* *}$ & $3.90 \pm 0.96^{* *}$ \\
A area (cm) & $3.17 \pm 0.48$ & $3.38 \pm 0.61$ & $3.75 \pm 0.47^{* *}$ \\
E/A area & $0.96 \pm 0.25$ & $1.11 \pm 0.28$ & $1.03 \pm 0.21$ \\
Peak E (cm/sec) & $34.5 \pm 5.6$ & $38.8 \pm 4.2^{*}$ & $42.2 \pm 7.3^{* *}$ \\
Peak A (cm/sec) & $42.7 \pm 6.1$ & $43.5 \pm 7.7$ & $49.3 \pm 7.9^{*}$ \\
Peak E/A & $0.82 \pm 0.13$ & $0.91 \pm 0.14$ & $0.87 \pm 0.17$ \\
Peak E/total velocity-time integral (/sec) & $5.65 \pm 0.88$ & $5.57 \pm 0.53$ & $5.57 \pm 0.71$ \\
\hline
\end{tabular}

$\mathrm{PA}$, pulmonary artery; TV, tricuspid valve; $\mathrm{HR}$, heart rate; $\mathrm{E}$ area, flow velocity-time integral of early diastolic filling; A area, flow velocity-time integral of atrial contraction; E/A area, ratio of $\mathrm{E}$ area to $\mathrm{A}$ area; Peak $\mathrm{E}$, peak velocity of early diastlic filling; Peak A, peak velocity of atrial contractio; Peak E/A, ratio of peak $\mathrm{E}$ to peak $\mathrm{A} ;{ }^{*} p<0.05,{ }^{* *} p<0.01$ (in comparison with $2 \mathrm{hr}$ ). 
$6.1 \mathrm{~cm} / \mathrm{sec}[p<0.05]$, respectively). The peak $\mathrm{E} / \mathrm{A}, \mathrm{E} / \mathrm{A}$ area, and peak $\mathrm{E} /$ total transtricuspid flow velocity-time integral did not show statistically significant changes from 2 to $24 \mathrm{hr}$.

Ductus arteriosus diameter. The inner diameter of the ductus arteriosus was
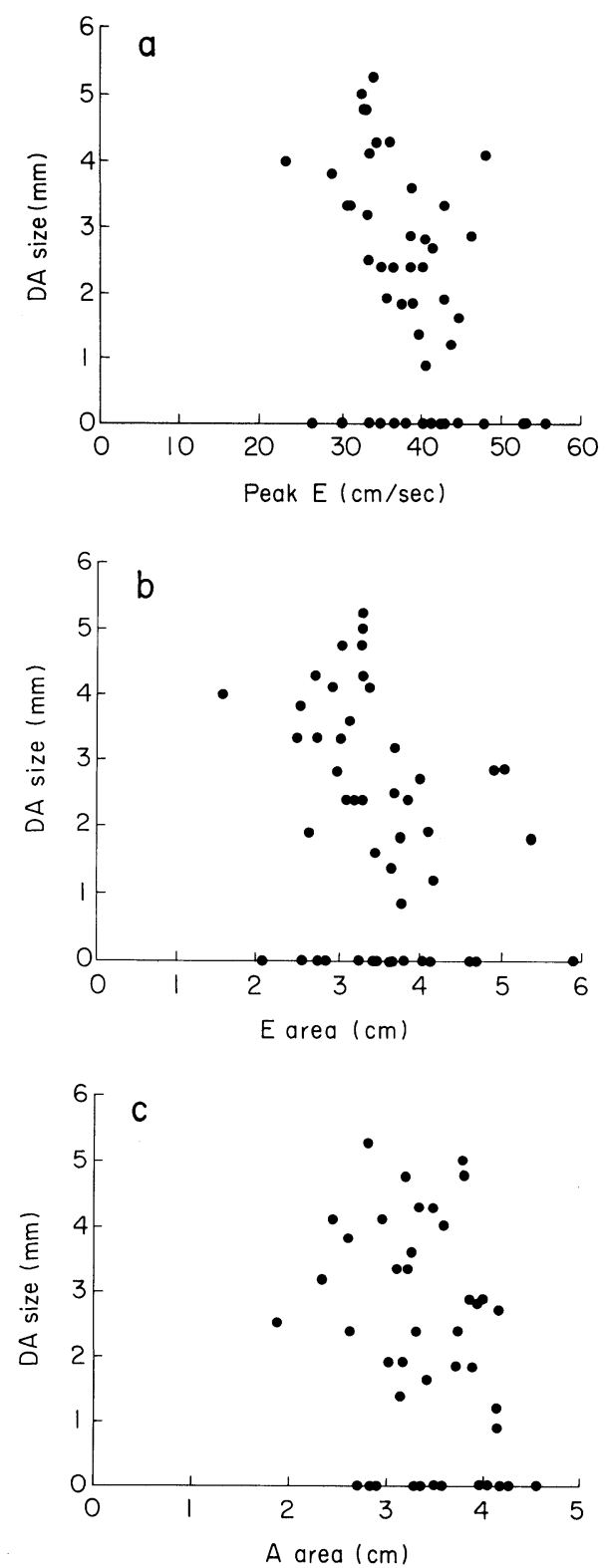

Fig. 2. Relation with the ductus arteriosus size and the peak $\mathrm{E}(2 \mathrm{a}), \mathrm{E}$ area (2b), and $A$ area (2c). The ductus arteriosus size showed a weak correlation with the peak $\mathrm{E}(\mathrm{r}=-0.46, p<0.05), \mathrm{E}$ area $(\mathrm{r}=-0.37, p<0.05)$, and $\mathrm{A}$ area $(\mathrm{r}=-0.34, p<0.05)$. DA, ductus arteriosus. Abbreviations as in Fig. 1 . 
$4.3 \mathrm{~mm} \pm 0.5 \mathrm{~mm}$ (mean \pm s.D.) at $2 \mathrm{hr}$. The ductus arteriosus closed in $2 / 16$ subjects $(12 \%)$ by $1 \mathrm{hr}$, and $14 / 16(88 \%)$ by $24 \mathrm{hr}$. The inner diameter at $12 \mathrm{hr}$ was $2.0 \pm 0.6 \mathrm{~mm}$ (mean \pm s.D.).

Relation between the ductus arteriosus size and indices of right ventricular diastolic filling. The ductus arteriosus size showed a weak inversely correlation with the peak $\mathrm{E}(\mathrm{r}=-0.46, p<0.05), \mathrm{E}$ area $(\mathrm{r}=-0.37, p<0.05)$, and $\mathrm{A}$ area $(\mathrm{r}=-0.34, p<0.05)$ (Fig. 2$)$. There was no correlation between the ductus arteriosus size and peak $\mathrm{A}$, peak $\mathrm{E} / \mathrm{A}$, and $\mathrm{E} / \mathrm{A}$ area.

\section{Discussion}

Among the various factors that can affect right ventricular filling, preload plays a significant role as similar in left ventricular filling. In fact, results of experimental studies (Ishida et al. 1986; Choong et al. 1988) have shown that instantaneous peak velocities of transmitral flow are strictly dependent on the atrioventricular pressure gradient and therefore on the left atrial pressure, which in turn is affected mainly by preload. Choong et al. (1987) reported that nitroglycerin altered the Doppler characteristics of the early filling wave. We have previously demonstrated the effects of ductus arteriosus on the left ventricular diastolic filling (Harada et al. 1994), however, little attention has been paid to right ventricular diastolic filling in the early neonatal period. To our knowledge, this is the first serial evaluation of the relation between right ventricular output changes and right ventricular diastolic filling changes in normal human subjects during the early neonatal period.

Serial right ventricular output change. In our present study, as in previous studies (Baylen et al. 1983; Takenaka et al. 1987), the PA flow velocity-time integral was calculated as an indicator reflecting right ventricular stroke volume. We assumed that the cross-sectional area of the pulmonary artery remained constant from 2 to $24 \mathrm{hr}$ after birth, so that any measured change in PA flow velocity-time integral would be reflective of change in stroke volume. In our study, as well as in that of Takenaka et al. (1987), the PA flow velocity-time integral was at the lowest level at $2 \mathrm{hr}$, but PA flow velocity-time integral at 24 hr increased by $50 \%$ of this value at $2 \mathrm{hr}$. Our study, as has been well known, showed that the ductus arteriosus remained widely patent shortly after birth with predominant left-to-right shunting. In a neonate with a left-to-right shunt through a ductus arteriosus, systemic flow equals main pulmonary artery flow, while pulmonary flow through the lung equals ascending aortic flow (Takenaka et al. 1987). Therefore, this shunt is likely to play a role in the decrease of the PA flow velocity-time integral at $2 \mathrm{hr}$. The increase in the PA flow velocity-time integral at $24 \mathrm{hr}$ could also be explained by a contribution of a left-to-right shunt through the foramen ovale, although, we could not evaluate the effects of the foramen ovale on the right ventricular diastolic filling because it was difficult to quantitate the amount of left-to-right flow volume through the foramen ovale. 
This shunt through the foramen ovale has been reported to be considerably smaller than that of the left-to-right shunt through the ductus arteriosus (Arcilla et al. 1967). Therefore, the dominant factor causing the increased PA flow velocitytime integral at $24 \mathrm{hr}$ has been considered to be due to the cessation of the left-to-right shunt through the patent ductus arteriosus. From our study, it appears that the increase in preload on the right ventricle occurred in the first 24 $\mathrm{hr}$.

Serial right ventricular filling change. There have been few reports on serial right ventricular diastolic filling changes in the early neonatal period. Furthermore, little is known about the impact of changes in loading condition on the transtricuspid flow pattern in neonates. Riggs et al. (1989) demonstrated that the right ventricular filling pattern at $12 \pm 6$ hours of age did not differ significant from that $24 \mathrm{hr}$ later on the 2 nd day of life. In our present study, sequential analysis of right ventricular filling from 2 to $24 \mathrm{hr}$ after birth demonstrated significant changes in peak $\mathrm{E}$, peak $\mathrm{A}, \mathrm{E}$ area, and $\mathrm{A}$ area. This discrepancy may be attributable to differences in the amount of shunt flow volume through the ductus arteriosus, since in all our subjects at $2 \mathrm{hr}$, the ductus remained widely patent with a predominant left-to-right shunting, while it was closed in 13 of 22 $(59 \%)$ of Riggs's subjects at $12 \pm 6 \mathrm{hr}$. In addition, we have demonstrated that the ductus arteriosus size was correlated with peak E, E area, and A area, suggesting that both of right ventricular early and late diastolic filling depend on the preload conditions. In contrast, Odake et al. (1991) have demonstrated in normal adult patients that the peak $\mathrm{E}$ increased significantly following dextran infusion with no change in peak A. However, the differential mechanisms regarding the neonate's and adult's right ventricular filling change in altered loading conditions is unknown. We speculate that the preload dependency of atrial contraction reflects reduced the right ventricular compliance as a result of intrauterine dominance.

The peak E/transtricuspid flow velocity-time integral was less variable than the peak $\mathrm{E} / \mathrm{A}$ or $\mathrm{E} / \mathrm{A}$ area, since both the peak $\mathrm{E}$ and transtricuspid flow velocitytime integral increased proportionately, while the peak E/A, E/A area, and peak $\mathrm{E} /$ transtricuspid flow velocity-time integral remained constant during the first 24 hr. Previous reports (Bowman et al. 1988; Miki et al. 1991) have shown that the peak $\mathrm{E} /$ total diastolic flow velocity-time integral was highly correlated with the radionuclide angiographic peak filling rate normalized to stroke volume. Moreover, unlike nonnormalized peak early flow velocity and peak E/A, which are the most commonly used Doppler variables, the peak E/total tricuspid flow velocitytime integral is not influenced by the sample volume or heart rate. Other investigator suggested (Triulzi et al. 1990) that the peak E/total transmitral flow velocity-time integral could potentially be an index independent from preload variations. For practical reasons, therefore, this index might be useful for evaluating right ventricular diastolic function in the early neonatal period. 
In the present study, the changes in preload and afterload has not been substantiated or quantified by invasive hemodynamic monitoring. However, we believe that the echocardiographic parameters we used should be considered reliable indicies of changes in preload. Right ventricular diastolic filling may be influenced by the changes in the right ventricular afterload. Vermilion et al. (1990) have demonstrated that right ventricular afterload was not the direct cause of abnormalities in right ventricular diastolic filling. We believe that the changes in right ventricular diastolic filling in this study is due to the altered preload conditions of right ventricle.

The redistribution of transtricuspid flow induced by preload conditions should be taken into account to interpretation of transtricuspid velocity patterns, in terms of diastolic function.

\section{References}

1) Appleton, C.P., Hatle, L.K. \& Popp, R.L. (1988) Demonstration of restrictive ventricular physiology by Doppler echocardiography. J. Am. Coll. Cardiol., 11, 757768.

2) Arcilla, R.A., Oh, W., Wallgren, G., Hanson, J.S., Gessner, I.H. \& Lind, J. (1967) Quantitative studies of the human neonatal circulation. II. Hemodynamic findings in early and late clamping of the umbilical cord. Acta Paediatr. Scand., 179, Suppl., 23-42.

3) Baylen, B.G., Ogata, H., Igegami, M., Jacobs, R.J, Jobe, A.H. \& Emmanouilides, G.C. (1983) Left ventricular performance and regional blood flows before and after ductus arteriosus occlusion in premature lambs treated with surfuctant. Circulation, 67, 837843.

4) Bowman, L.K., Lee, F.A., Jaffe, C.C., Wackers, F.J.T.H. \& Zaret, B.L. (1988) Peak filling rate normalized to mitral stroke volume: A new Doppler echocardiographic filling index validated by radionuclide angiographic techniques. J. Am. Coll. Cardiol., 12, 937-943.

5) Castini, D., Mangiarotti, E., Vitolo, E., Conconi, B. \& Triulzi, M.O. (1992) Effects of venous return reduction in hypertensive patients: Is there a Doppler diastolic dysfunction index independent of preload reduction? Am. Heart J., 123, 1299-1306.

6) Choong, C.Y., Herrmann, H.C., Weyman, A.E. \& Fifer, M.A. (1987) Preload dependence of Doppler-derived indexes of left ventricular diastolic function in humans. $J$. Am. Coll. Cardiol., 10, 800-808.

7) Choong, C.Y., Abascal, V.M., Thomas, J.D., Guerrero, J.L., McGlew, S. \& Weyman, A.E. (1988) Combined influence of ventricular loading and relaxation on the transmitral flow velocity profile in dogs measured by Doppler echocardiography. Circulation, 78, 672-683.

8) Courtois, M., Vered, Z., Barzilai, B., Ricciotti, N.A., Perez, J.E. \& Ludbrook, P.A. (1988) The transmitral pressure-flow velocity relation: Effect of abrupt preload reduction. Circulation, 78, 1459-1468.

9) Harada, K., Shiota, T., Takahashi, Y., Tamura, M., Toyono, M. \& Takada, G. (1994) Doppler echocardiographic evaluation of left ventricular output and left ventricular diastolic filling changes in the first day of life. Pediatr. Res. (in press)

10) Hatle, L.K., Appleton, C.P. \& Popp, R.L. (1989) Differentiation of constrictive pericarditis and restrictive cardiomyopathy by Doppler echocardiography. Circulation, 79, 357-370.

11) Ishida, Y., Meisner, J.S., Tsujioka, K., Gallo, J.I., Yoran, C., Frater, R.W.M. \& Yellin, 
E.L. (1986) Left ventricular filling dynamics: Influence of left ventricular relaxation and left atrial pressure. Circulation, 74, 187-196.

12) Johnson, G.L., Moffett, C.B. \& Noonan, J.A. (1988) Doppler echocardiographic studies of diastolic ventricular filling patterns in premature infants. Am. Heart J., 116, 1568-1574.

13) Klein, A.L., Hatle, L.K., Burstow, D.J., Taliercio, C.P., Seward, J.B., Kyle, R.A., Bailey, K.R., Gertz, M.A. \& Tajik, A.J. (1990) Comprehensive Doppler assessment of right ventricular diastolic function in cardiac amyloidosis. J. Am. Coll. Cardiol., 15, 99-108.

14) Miki, S., Murakami, T., Iwase, T., Tomita, T., Nakamura, Y. \& Kawai, C. (1991) Doppler echocardiographic transmitral peak early velocity does not directly reflect hemodynamic changes in humans: Importance of normalization to mitral stroke volume. J. Am. Coll. Cardiol., 17, 1507-1516.

15) Nascimento, R., Cunha, D.L., Bastos, P., VanZeller, P. \& Rodrigues-Gomes, M. (1991) Echo-Doppler study of right ventricular filling in asymptomatic patients with senning operation for transposition of the great arteries. Am. J. Cardiol., 68, 693-695.

16) Odake, M., Takeuchi, M. \& Fukuzaki, H. (1991) Doppler assessment of right ventricular filling dynamics during volume loading in ischemic heart disease. Clin. Cardiol., 14, 402-408.

17) Riggs, T.W., Rodriguez, R., Snider, A.R., Batton, D., Pollock, J. \& Sharp, E.J. (1989) Doppler echocardiographic evaluation of right and left ventricular diastolic function in normal neonates. J. Am. Coll. Cardiol., 13, 700-705.

18) Takenaka, K., Waffarn, F., Dabestani, A., Gardin, J.M. \& Henry, W.L. (1987) A pulsed Doppler echocardiographic study of the postnatal changes in pulmonary artery and ascending aortic flow in normal term newborn infants. Am. Heart J., 113, 759766.

19) Triulzi, M.O., Castini, D., Ornaghi, M. \& Vitolo, E. (1990) Effects of preload reduction on mitral flow velocity pattern in normal subjects. Am. J. Cardiol., 66, 995-1001.

20) Vermilion, R.P., Snider, A.R., Meliones, J.N., Peters, J. \& Merida-Asmus, L. (1990) Pulsed Doppler evaluation of right ventricular diastolic filling in children with pulmonary valve stenosis before and after balloon valvuloplasty. Am. J. Cardiol., 66, 79-84.

21) Vermilion, R.P., Snider, A.R., Bengur, A.R. \& Meliones, J.N. (1991) Long-term assessment of right ventricular diastolic filling in patients with pulmonic valve stenosis successfully treated in childhood. Am. J. Cardiol., 68, 648-652.

22) Wilson, N., Reed, K., Allen, H.D., Mark, G.R. \& Goldberg, S.J. (1987) Doppler echocardiographic observations of pulmonary and transvalvular velocity changes after birth and during the early neonatal period. Am. Heart J., 113, 750-758. 